\title{
En route vers la compréhension de la kystogenèse dans la polykystose rénale
}

L'année dernière, le consortium européen avait fait des progrès décisifs dans l'identification du gène $P K D 1$ dont les mutations sont responsables d'environ $85 \%$ des cas de polykystose rénale autosomique dominante (ADPKD) (voir $\mathrm{m} / \mathrm{s} \mathrm{n}^{\circ} 10$, vol. 10 , p. 1050). Les difficultés rencontrées depuis plusieurs années dans l'isolement du gène $P K I) l$ tiennent en partie au fait que plusieurs copies d'une grande partie de ce gène sont présentes en $16 p$, situées de façon plus proximale que $P K D 1$, aboutissant à des transcrits dont la séquence est très proche de celle de PKI)1. Très récemment, le consortium international, un consortium américain et le consortium européen viennent de livrer les données sur la structure complète de PKDI [1-3], laissant entrevoir les propriétés de la protéine codée, appelée polycystine. Probablement du fait de la complexité des techniques nécessaires à son identification, des différences de séquences persistent entre les différents groupes, notamment vis-à-vis de la séquence publiée initialement par le consortium européen, puisqu'une insertion de deux cytosines en 3' de l'ADNc modifie le cadre de lecture initialement prédit et conduit au remplacement des 92 acides aminés carboxy-terminaux par 12 nouveaux résidus.

Le gène $P K D l$ s'étend sur $52 \mathrm{~kb}$, comporte 46 exons formant un transcrit primaire de $14,5 \mathrm{~kb}$ codant pour une protéine de 4302 acides aminés, d'une masse molaire estimée à $460 \mathrm{kDa}$. Le transcrit primaire semble pouvoir subir un épissage alternatif. La région $\mathrm{NH} 2$ terminale débute par un peptide signal de potentiel de clivage. Immédiatement en aval, codées par les exons 1 à 4 , se trouvent deux répétitions riches en leucine (LRR, leucine-rich repeats) encadrées par deux régions riches en cystéine. Ces structures appartiennent toujours à des domaines protéiques extracellulaires et semblent impliquées dans des interactions protéine-protéine telles que la reconnaissance cellulaire, la liaison à des composants de la matrice extracellulaire ou en tant que récepteur impliqué dans la transduction d'un signal. Les membres de cette superfamille sont, par exemple, les glycoprotéines plaquettaires d'adhérence, la protéine de la drosophile Slit et la famille des récepteurs de neurotrophines Trk. Les exons 6 et 7 codent pour un domaine unique analogue aux lectines dépendant du calcium, comme par exemple les sélectines et les récepteurs des sialoglycoprotéines, impliquées dans la liaison extracellulaire à des résidus glucidiques. Seul le consortium international [1] a identifié un module de lipoprotéine de faible densité (LDL-A), identifié originellement dans le récepteur des LDL mais présent également dans la portion extracellulaire de nombreuses protéines. L'exon 5 et les exons 11 à 15 codent pour 16 copies d'un nouveau domaine d'environ 80 acides aminés dénommé $\mathrm{PKD}$, analogue aux domaines immunoglobulines rencontrés dans certaines glycoprotéines de surface et molécules d'adhérence. Le groupe d'Oxford [2] a, en outre, détecté quatre domaines analogues à la fibronectine de type III (FNIII), retrouvés dans des protéines de la matrice extracellulaire et dans des molécules d'adhérence. De plus, ces auteurs proposent l'existence de onze domaines transmembranaires à l'extrémité carboxyterminale de la molécule (environ 1500 acides aminés) avec un court fragment de 230 acides aminés intracytoplasmique (figure 1). Cependant, la possibilité que la polycystine soit une molécule strictement extracellulaire n'est pas exclue [1]. Quoi qu'il en soit, il semble bien que la polycystine puisse jouer un rôle important dans les interactions cellule-cellule et cellulematrice extracellulaire. Ces interactions sont indispensables à la différenciation épithéliale, et donc à la tubulogenèse rénale. Une mutation de la polycystine pourrait supprimer les signaux en provenance de la matrice extracellulaire nécessaires à une morphogenèse tubulaire correcte et favoriser ainsi la kystogenèse. De même, un rôle important de la polycystine dans les relations cellulematrice extracellulaire d'autres tissus rendrait compte des manifestations extrarénales de l'ADPKD, telles que les anévrismes intracrâniens ou les anomalies des valves cardiaques. Les études en cours par hybridation in situ et immunohistochimie seront très précieuses pour déterminer la localisation précise de la polycystine et l'identité de ses partenaires extracellulaires. Concernant ce point, l'étude récente rapidement publiée dans Nature Medicine [4] a été réalisée à l'aide d'un anticorps reconnaissant la partie la plus carboxy-terminale de la protéine décrite initialement par le consortium européen et qui, en fait, n'existe plus dans la séquence consensus actuelle (voir supra)! Il est cependant tout à fait extraordinaire que ces auteurs aient ainsi décrit une protéine d'un PM similaire à celui de 


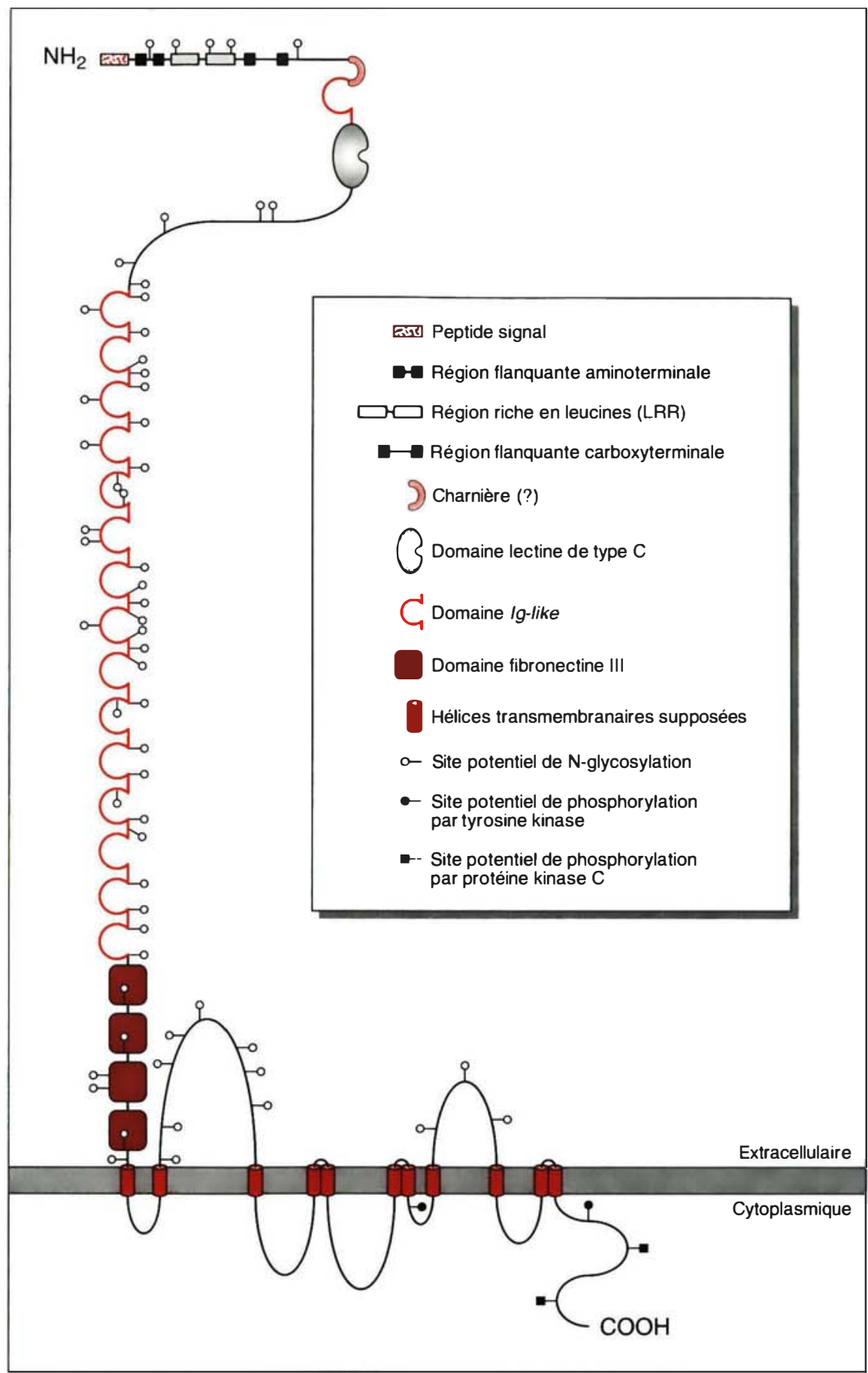

la polycystine présente dans la matrice extracellulaire non seulement du rein mais aussi du foie et des vaisseaux cérébraux, autres organes cibles de la maladie ! Cela doit faire envisager la possibilité d'un épissage alternatif de $P K D 1$ qui donnerait bien naissance à $\mathrm{m} / \mathrm{s} n^{\circ} 9$, vol. 11 , septembre 95
Figure 1. Modèle proposé pour le produit du gène PKD1, la polycystine. Comportant 4302 acides aminés la polycystine est une protéine essentiellement extracellulaire, formée de domaines très divers qui pourraient jouer un rôle dans les interactions des cellules entre elles et avec la matrice extracellulaire. On note : des répétitions riches en leucine (LRR) encadrées de régions riches en cystéine qui pourraient être impliquées dans des interactions protéiques de reconnaissance cellulaire; un domaine analogue aux lectines dépendantes du calcium, impliquées dans la liaison extracellulaire à des résidus glucidiques; des domaines immunoglobulines et fibronectine III, analogues à ceux rencontrés dans les molécules d'adhérence ; un domaine transmembranaire (11 passages possibles) et un domaine cytoplasmique avec des sites potentiels de phosphorylation. (D'après [2].)

The International Polycystic Kidney Disease Consortium. Polycystic kidney disease: the complete structure of the $P K J) I$ gene and its protein. Cell $1995 ; 81: 289-98$

2. Hughes J, Ward (:J, Peral B, Aspinwall R, (ilark K, San Millan J, ('amble V, Harris P. The polycystic kidney disease $1(P K D) 1)$ gene encodes a nove protein with multiple cell recognition domains Nature (ienet $1995 ; 10$ : 151-9.

3. The American PKDl Consortium Analysis of the genomic sequence $f(r)$ autosomal dominant polycystic kidney disease $(P K D) I$ ) gene predicts the presence of a leucine-rich repeat. Hum Mol Cenet $1995 ; 4: 575-82$

4. van Adelsberg JS, Frank D. The PKD)I gene produces a developmentally regulated protein in

B.K. mesenchyme and vasculature. Nature Med 1995 J.P.G. $1: 359 \cdot 64$.

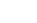

(1) 